\title{
An analysis of positive general transfer in discrimination learning in the rat
}

\author{
GEOFFREY HALL \\ University of Sussex, Brighton, England
}

\begin{abstract}
As a result of learning a single discrimination problem, rats and pigeons will show positive transfer to totally new discriminations. It has been suggested that this transfer effect reflects the deveropment of a process of general attentiveness. However, alternative explanations of the transfer effect are available which do not require any radical departure from traditional discrimination learning theory. The three experiments reported here demonstrate positive general transfer in rats trained on a simultaneous discrimination and tested under conditions which rule out these alternative explanations. The experiments also attempt to specify the nature of the processes underlying the general transfer effect.
\end{abstract}

When animals solve a discrimination problem, they may learn more than just those habits which enable them to show a preference for one stimulus over another. With primate subjects, general transfer effects have been amply demonstrated in experiments on learning set formation. More recently it has been suggested that the equivalent of a learning set may be formed by rats and by pigeons as a result of their learning a single simple discrimination. For example, Honig (1969) has shown that pigeons which are first trained on a successive free-operant discrimination between two stimuli and are then trained to respond to a new and different stimulus show strong control by this stimulus in a final generalization test. Control subjects given pseudodiscrimination (PD) training in the first stage (training in which the periods of reward and nonreward are not correlated with the training stimuli), or given single-stimulus training, show only weak stimulus control. Thomas, Freeman, Svinicki, Burr, and Lyons (1970) have replicated and extended this finding and interpret their results as evidence for a mechanism of "general attentiveness." Discrimination training, by raising an animal's level of general attentiveness, is held to enhance the readiness with which the animal will attend to and learn about all other stimuli.

Support for this interpretation has been sought in experiments which look at the effects of discrimination training with one set of stimuli upon the learning of a second problem with totally new stimuli (an extra-dimensional shift). It has been found (Eck, Noel, \& Thomas, 1969; Keilitz \& Frieman, 1970; Frieman \& Goyette, 1973) that birds given initial true discrimination (TD) training learn the second problem more rapidly than birds given initial PD training or birds given pretraining with just a single stimulus. Thomas, Miller, \& Svinicki (1971) have found this effect in rats trained initially with bright and dim houselights and then shifted to a discrimination between tones.

Work supported by a grant from the United Kingdom Science Research Council.
The hypothesis to be examined in the experiments reported below is that animals given true discrimination training are capable of learning that stimulus differences can serve as predictors of reinforcement and that they will transfer their learning to discriminations involving new stimuli. Although the results just cited are consonant with this hypothesis, they cannot supply conclusive proof. There are two major difficulties. First. it may be possible to explain the findings without recourse to any concept which requires the animals to transfer their learning from one set of stimuli to a completely different set. It is known, for instance, that discrimination training, in contrast to the various control treatments, reduces the control exerted by irrelevant stimuli present in the training situation (Wagner, Logan, Haberlandt, \& Price, 1968). These stimuli, which will still be present in the test situation, might otherwise act to mask the presence of control by stimuli that the experimenter is manipulating (Tumer \& Mackintosh, 1972) or might interfere with new learning. It seems particularly likely that the differential neutralization of irrelevant cues produced by TD and PD training accounts, at least in part, for differences found in the extradimensional shift.

Secondly, even if we accept that these results might imply a general transfer effect of the type observed in the formation of learning sets, it is by no means clear that the effect is a positive or helpful one. Mackintosh (1973) has argued in favor of a process of "leamed irrelevance"; he has suggested that animals may learn that stimuli are not correlated with reinforcement and that such learning will be a hindrance should the animals subsequently be required to learn that the stimuli are correlated with reward. It is possible that animals given PD or single-stimulus training might leam the irrelevance of the stimuli and that this learning might transfer to new stimuli. (There is certainly experimental evidence to show that rats given PD training learn an extradimensional shift less rapidly than untreated controls; Mandler, 1966; Bainbridge, 1973). It follows 
that a difference between a group of animals given TD training and its control group might be the result of a retardation of learning in the latter rather than a facilitation in the former. It is difficult to think of a control treatment that is not open to this criticism. The use of an untreated control is ruled out since any advantage shown by a trained group over an untrained control could be put down to the extra habituation to the experimental situation that the former had received.

The present experiments are designed to overcome these difficulties and to demonstrate unambiguously a positive general transfer effect. They do not try to disconfirm the theories outlined above; it is accepted that positive and negative general transfer effects are a possibility and that the neutralization of irrelevant cues by TD training is a reality. Rather, it is argued that the existence of these various effects renders inconclusive those experiments which have previously been taken as evidence for positive general transfer. As a first step, therefore, we must arrange a situation in which a difference between groups on an extradimensional shift cannot be explained away as due to a retardation in the control group. The experiments reported here do this by comparing the shift performance of an experimental group given prior discrimination training with that of an untrained control group. Of course, since the neutralization of irrelevant cues will put the experimental group at an advantage in the test phase, a superiority of the experimental over the control group could be solely due to this effect and would not prove the hypothesis to be examined in Experiment I-the hypothesis that discrimination training produces a "leamed relevance" effect which transfers from one set of stimuli to another. Accordingly, the strategy of the experiment is to provide as a test situation not a simple extradimensional shift but one in which learned relevance will result in negative transfer. If it is found that the experimental group is retarded with respect to the control group in solving the test problem (in spite of the various advantages that discrimination training might be expected to bestow), evidence for a strong general transfer effect would be provided.

\section{EXPERIMENT I}

The experiment consisted of two stages, initial training followed by a test problem. This latter was a probability learning task with black and white stimuli, one stimulus being the positive on $70 \%$ of the trials and the negative on the remaining $30 \%$ of the trials. When rats are trained by a noncorrection procedure on such a problem, they come to choose the "majority stimulus" on all trials (i.e., they "maximize"). One group of subjects (the control group) was given no training (apart from basic pretraining) before being presented with the probability problem, the experimental group was given prior training on a consistently reinforced orientation discrimination, and the performance of the two groups was compared on the probability problem. The second group should benefit from any advantage that derives from its extra experience of handling, of the training situation, and so on, and it will also benefit from any suppression of irrelevant cues that might occur. If these subjects learn, in addition, that th əre are stimuli which reliably predict the occurrence of reward, such learning might be expected to deter them from adopting a maximizing strategy; a strategy which requires them to continue to respond to one stimulus despite the fact that they are sometimes not rewarded for doing so. This expectation is derived from Goodnow's (1955) observation that the failure of human subjects to maximize on a probability learning task stems, in part, from their belief that $100 \%$ success is possible. In an experiment with rats, Solomon (1962) has provided some evidence in favor of this notion by showing that rats raised in a constant early environment are less likely to maximize than rats raised in an environment that varies in many respects from day to day.

\section{Method}

Subjects. The subjects were 16 male hooded rats. They were maintained on a schedule of food deprivation, food being available for only the $2 \mathrm{~h}$ each day that followed experimental treatment.

Apparatus. The apparatus was a jumping stand. It consisted of a goalbox with two adjacent apertures and with small landing platforms $15 \mathrm{~cm}$ wide and $8 \mathrm{~cm}$ deep fixed in front of each opening. A vertical partition $12 \mathrm{~cm}$ deep prevented animals from stepping from one landing platform to the other. The rats jumped from a stand shaped like a small elevated $Y$ maze; its overall length was $20 \mathrm{~cm}$ and its arms, $9 \mathrm{~cm}$ long and $7 \mathrm{~cm}$ wide, directly faced the goalbox apertures. The goalbox doors, $15 \mathrm{~cm}$ square, were themselves the stimulus objects. In pretraining, two identical gray doors were used. During training on the orientation discrimination, the doors bore alternating black and white stripes, $1 \mathrm{~cm}$ wide, which ran horizontally (Stimuli $\mathrm{H}$ ) or vertically (V). For the probability problem, the doors were black (B) and white (W).

Procedure. The animals were given 55 pretraining trials spread over 9 days. During the first 15 trials, a single gray goalbox door was locked in place, randomly on the left and on the right. The subjects could therefore cross from the stand and enter the goalbox through one of the apertures and could eat from the baited foodcup. On the remaining 40 pretraining trials, two gray doors were in place, one of them unlocked. The subjects learned to push down the unlocked door and to enter the goalbox. The gap between the stand and the goalbox, which on the 1 st day of pretraining was $2 \mathrm{~cm}$, was gradually increased, reaching $17 \mathrm{~cm}$ by the end of pretraining. This gap was sufficiently wide that the animals had to jump across it. If an animal jumped to the locked door, it was returned to the stand and allowed to jump again and thus, during pretraining, each animal was rewarded each time it was put in to the apparatus.

Ten trials of discrimination training were given each day. Noncorrection procedure was used; after a correct response, the animal gained access to the goalbox, which contained four $45-\mathrm{mg}$ food pellets, while after an incorrect response, the animal was detained for $10 \mathrm{sec}$ on the landing platform in front of the locked goalbox door before being returned to its holding cage. The positive, or majority, stimulus appeared equally often on the left and on the right, its position being determined according to a modified Gellermann sequence. The interval between trials was 
about 5 min. Eight animals chosen at random were trained on the probability problem, four subjects with $B$ as the majority stimulus and four with $W$. Response to the majority stimulus was rewarded on seven trials each day, response to the minority stimulus on the remaining three. Training was cont inued for 400 trials unless the problem was solved earlier. The uriterion of learning was 18 choices of the majority stimulus over 2 days, with the last 10 responses all being made to the majority stimulus. The remaining eight subjects were trained initially on the orientation discrimination; half with $H$ positive and half with $\mathrm{V}$ positive. After reaching cirterion on this problem, they were given 2 days of overtraining and were then transferred to the probability problem, half of each subgroup having $B$ as their najority stimulus and half having $W$.

\section{Results}

Table 1 presents trials and errors to criterion for both stages of the experiment; the scores include performance on the 2 days over which the criterion was reached. During probability learning, a response to the minority stimulus was scored as an error. The experimental group clearly learned the probability problem more readily than the control group, making fewer errors (Mann-Whitney $U$ test, $U=13, p<.05$ ) and needing fewer trials to reach criterion $(U=11, p<.03)$. Two subjects in the control group failed to learn the probability problem, but all other subjects maximized. No animal showed any tendency to minimize (consistently to choose the minority stimulus).

\section{Discussion}

Rats that have learned an orthodox simultaneous discrimination readily solve a probability problem. There is no sign that experience of a consistent stimulus-reinforcer relationship hinders the learning of a discrimination in which the stimulus-reinforcer relationship is only probabilistic. There seems to be three possible accounts of this finding. First is the possibility that there is no "learned relevance" effect; that there is no source of general transfer in discrimination training apart from the beneficial effects produced by experience of handling and by the neutralization of irrelevant cues. Secondly, it remains possible that discrimination training does indeed induce in the rats a tendency to seek out consistent stimulus-reinforcer relationships but that the size of the negative transfer effect produced in this way is insufficient to overcome the positive effects that we know to be present. In view of the large difference between the experimental and control groups seen on the test problem, both these possibilities seem unlikely. Therefore, a third worth considering is that discrimination training produces some general transfer effect, other than those already mentioned, which helps probability learning. For example, if during discrimination training, the rats learn that, of the two stimuli, one is a better predictor of reward than the other (or, in different terminology, that one stimulus of the pair is to be approached and one to be avoided),
Table 1

Experiment I: Group Mean Scores in Training and Transter

\begin{tabular}{ccc} 
& \multicolumn{2}{c}{ Group } \\
\cline { 2 - 3 } & Experimental & Control \\
\hline Training & & \\
Trials & 141.25 & \\
Frrots & 60.87 & \\
Transfier & & \\
Trials & 102.50 & 270.00 \\
Errors & 45.62 & 124.00 \\
\hline
\end{tabular}

then the transfer of this learning would help them to maximize on a probability problem. The experiments reported below provide a test of this new hypothesis.

\section{EXPERIMENTS II AND III}

These experiments follow the basic design of Experiment I. In each of them, an experimental group of subjects is given discrimination training, and its performance on a test problem is compared with that of an untrained control group. As in Experiment $I$, the test problem was designed to be one in which two sets of factors are played off one against the other; with this test problem, the neutralization of irrelevant cues should help learning while the transfer of a tendency to approach one stimulus and to avoid the other should produce negative transfer. Again, in order to demonstrate the general transfer effect in which we are interested, it is necessary to find an overall negative transfer effect. The test problem chosen required the animals to altemate between stimuli, black and white each being rewarded on altemate trials. If animals given discrimination training on an orientation problem transfer a tendency to approach one stimulus of a pair and to avoid the other, then they should perform poorly on this problem.

Experiments II and III were identical in design and differed only in details of the training technique.

\section{Method}

The subjects in each experiment were 16 naive male hooded rats maintained as in Experiment I. The apparatus and pretraining procedures were exactly as in that experiment. In Experiment II, eight subjects were trained initially on the $H$ against $\mathrm{V}$ discrimination, half with $\mathrm{H}$ positive and half with $\mathrm{V}$ positive. A correction procedure was used. After an incorrect choice, the rat was detained for $10 \mathrm{sec}$ on the landing platform, was then replaced on the stand and allowed to jump again. If the rat repeated its incorrect choice, it again was put back on the stand and gently pushed toward the correct goalbox door, guidance that was invariably enough to elicit a jump to the correct alternative. This training procedure yields two scores, initial or first-jump errors, and total errors made in reaching criterion. To reach criterion, a subject was required to make no more than two errors over 2 days with the last day's responses all correct. After reaching criterion on the orientation problem, the Experimental group was given 2 days of overtraining and was then transferred to the alternation problem with $B$ and $W$ stimuli. The stimulus that was to be positive on the first trial of 
Table 2

Experiments II and III: Group Mean Scores in Training and Transfer

\begin{tabular}{|c|c|c|c|c|}
\hline & \multicolumn{2}{|c|}{ Experiment II } & \multicolumn{2}{|c|}{ Experiment III } \\
\hline & $\begin{array}{l}\text { Experi- } \\
\text { mental } \\
\text { Group }\end{array}$ & $\begin{array}{c}\text { Control } \\
\text { Group }\end{array}$ & $\begin{array}{l}\text { Experi- } \\
\text { mental } \\
\text { Group }\end{array}$ & $\begin{array}{l}\text { Control } \\
\text { Group }\end{array}$ \\
\hline \multicolumn{5}{|l|}{ Training } \\
\hline Initial Errors & 27.00 & & 23.50 & \\
\hline Total Errors & 30.00 & & 24.50 & \\
\hline \multicolumn{5}{|l|}{ Transfer } \\
\hline Initial Errors & 87.12 & 75.50 & 86.75 & 71.25 \\
\hline Total Errors & 100.00 & 84.00 & 98.62 & 73.63 \\
\hline
\end{tabular}

each day was chosen at random, and errors made on this trial were not scored. The eight subjects in the control group were trained from the outset on the alternation problem. All subjects were given 20 days of alternation training.

The correction procedure used in Experiment II was an attempt to facilitate learning of the alternation problem, which is a difficult one. We cannot expect differences between groups to show up if most animals fail to make any progress toward solution. In Experiment III, another change was made to speed the learning of the test problem. The intertrial interval was reduced from $5 \mathrm{~min}$ to $10 \mathrm{sec}$. In all other respects, Experiment III was an exact replicate of Experiment II.

\section{Results}

The results of both experiments are given in Table 2 . The direct comparison of the data of these two experiments may be open to question because they were carried out at different times with rats drawn from different populations, but such a comparison suggests that massed training leads to more efficient learning of the oreintation problem than does spaced training. Less surprising is the marked superiority of these subjects over those trained by noncorrection on the same problem in Experiment I (Table 1).

On the transfer test, the experimental groups performed less well than the control groups. In Experiment II, the groups differed both in their initial error scores $(U=9, p<.02)$ and in their total error scores $(U=11, p<.03)$; in Experiment III, these differences were again statistically significant $(U=1.5$, $\mathrm{p}<.001$, and $U=0, p<.001$ ). Although reliable, the differences between groups were small; all subjects clearly found the alternation problem difficult, and none showed signs of achieving consistently accurate performance.

In order to identify "hypotheses" or consistent response patterns, performance over the first 5 days of the transfer test was analyzed in more detail. In particular, it was hoped that the experimental groups might show a greater tendency to respond consistently to one stimulus ( $\mathrm{B}$ or $\mathrm{W}$ ) than the control groups. Accordingly, the number of days on which each animal made at least 8 of its 10 response to one stimulus was scored. The mean scores for both groups in Experiment II was .75; in Experiment III, a difference was found in the expected direction but was not statistically significant $(U=29)$, the experimental group having a mean of 1.37 and the control group of .87 . A similar analysis of position responding provided little evidence for the suppression of position habits in the experimental group. Calculating the number of days on which at least 8 of the 10 responses were to one position yielded mean scores of 1.75 and 2.25 for the experimental and control groups in Experiment II and 1.50 and .87 for these groups in Experiment III. Neither difference was statistically reliable $(U=32$ and $U=27)$.

\section{Discussion}

Rats trained on an orthodox simultaneous discrimination between horizontal and vertical stimuli are hindered in learning a problem which requires them to alternate between black and white stimuli. There is thus some transfer effect produced by discrimination training which is sufficiently strong that it can overcome the known beneficial effects of such training and result in overall negative transfer. Although the transfer produced in this special test situation is negative, the same process will be active when the transfer test is a simple extradimensional shift, and, in this case, it presumably acts to help new learning. An effect of this sort, al though often postulated, has not previously been adequately demonstrated since the experimental designs usually used have not been able to exclude the action of other simple transfer effects.

Can we be more specific about the nature of the positive general transfer? Traditionally, it has been referred to as the result of a "set to discriminate" or of heigh tened "general attentiveness" but these labels seem uninformative descriptions rather than explanations. Thus, to say that discrimination training produces a set to discriminate does not help us to explain why this training helps the learning of a probability problem but retards performance on alternation. (A similar argument can be used against attempts to explain the present results in terms of the development of simple observing responses).

The hypothesis outlined above, that discrimination training teaches the animal that of two stimuli one is to be preferred over the other, has the virtue of explaining the facilitation of probability learning and the retardation seen on alternation. But it creates two problems of its own. First, a number of alternative statements of the hypothesis are available. We could say, for example, that discrimination training teaches the animal to approach one stimulus and to avoid the other or, again, simply that discrimination training teaches the animal not to alternate between stimuli. The extent to which these are real altematives rather than mere rewordings requires consideration. And secondly, a more formal specification of the mechanism by which this proposed general transfer effect operates is clearly needed. 


\section{REFERENCES}

Bainbridge, P. L. Learning in the rat: Effect of early experience with an unsolvable problem. Joumal of Comparative and Physiological Psychology, 1973, 82, 301-307.

Eck, K. O.. Noel, R. C., \& Thomas. D. R. Discrimination learning as a function of prior discrimination and nondifferential training. Joumal of Experimental Psychology, 1969,82, 156-162.

Frieman, J., \& Goyette, C. H. Transfer of training across stimulus modality and response class. Joumal of Experimental Psychology, 1973, 97, 235-241.

Goodnow, J. J. Determinants of choice-distribution in two-choice situations. American Journal of Psy chology. 1955. $68,106-116$.

Honig, W. K. Attentional factors governing the slope of the generalization gradient. In R. M. Gilbert and N. S. Sutheriand (Eds.), Animal discrimination leaming. London: Academic Press. 1969.

Keilitz, I. \& Frieman, J. Transfer of training following errorless discrimination learning. Journal of Experimental Psychology, $1970,85,293-299$.

Mackintosh, N. J. Stimulus selection: Learning to ignore stimuli that predict no change in reinforcement. In $R$. A. Hinde and $J$.
Stevenson-Hinde (Eds.), Constraints on leaming. London: Academic Press, 1973.

Mandler, J. M. Behavior changes during overtraining and their effects on reversal and transfer. Psychonomic Monograph Supplements, 1966, 1, 187-202.

Solomon, S, Effects of variations of rearing, drive level, and training procedures on performance in probability leaming tasks. Psy chological Reports, 1962, 10,679-689.

Thomas, D. R. Freeman, F Siinicki, J, G Burr, D. E. S., \& Lyons, J. Effects of extradimensional training on stimulus generalization. Joumal of Expenmental Psychology IIonograph, $1970,83,1-21$.

Thomas D. R Niller, J T \& Stinicki, J G Nonspecific transfer effects of discrimination training in the rat. Joumal of Comparative and Physiological Psychology, 1971, 74, 96-107. Tumer. C.. \& Mackintosh, N.J. Stimulus selection and irrelevant stimuli in discrimination learning by pigeons. Joumal of Comparative and Phsyiological Psychology, 1972, 78, 1-9.

Wagner, A. R., Logan. F. A.. Haberlandt, K.. \& Price, T. Stimulus selection in animal discrimination learning. Joumal of Experimental Psychology. 1968, 76, 171-180.

(Received for publication October 9, 1974: revision accepted January 30,1975 .) 